\title{
Effects of Short-term Water Stress, Hydrophilic Polymer Amendment, and Antitranspirant on Stomatal Status, Transpiration, Water loss, and Growth in 'Better Boy' Tomato Plants
}

\author{
Sanliang $\mathbf{G u}^{\mathbf{1}}$ \\ Department of Fruit Science, Southwest Missouri State University, Research Campus, Mountain Grove, \\ MO 65711 \\ Leslie H. Fuchigami ${ }^{2}$ and Sung H. Guak ${ }^{3}$ \\ Department of Horticulture, Oregon State University, ALS 4017, Corvallis, OR 97331 \\ Charles Shin ${ }^{4}$ \\ Great Lake Chemical Corp., P.O. Box 2200, Highway 52, N.W., West Lafayette, IN 47906 \\ Additional index words. stomatal conductance, plant height, biomass, Lycopersicon esculentum
}

\begin{abstract}
Seedling plugs of 'Better Boy' tomato plants (Lycopersicon esculentum Mill.) were potted in $60 \%$ processed fiber : $40 \%$ perlite (by volume) media amended or nonamended with either crystalline or powdered hydrophilic polymer (2.4 $\left.\mathrm{kg} \cdot \mathrm{m}^{-3}\right)$, and treated with one of several concentrations $(0 \%, 2.5 \%, 5 \%, 7.5 \%$, and $10 \%)$ of antitranspirant GLK-8924, at the four true-leaf stage. Plants were either well-irrigated or subjected to short-term water stress, withholding water for 3 days, after antitranspirant GLK-8924 application. Leaf stomatal conductance, transpiration rate, whole-plant transpirational water loss, and growth were depressed by short-term water stress and antitranspirant GLK-8924. In contrast, hydrophilic polymer amendment increased plant growth, resulting in higher transpirational water loss. The depression of stomatal conductance and transpiration rate by short-term water stress was reversed completely in 2 days after rewatering while the reduction of plant growth rate diminished immediately. The effects of antitranspirant GLK-8924 were nearly proportional to its concentration and lasted 8 days on stomatal conductance and transpiration rate, 4 days on plant growth rate, and throughout the experimental period on plant height and transpirational water loss. Plant growth was reduced by antitranspirant GLK-8924 possibly by closing leaf stomata. In contrast, hydrophilic polymer amendment resulted in larger plants by factors other than influences attributed to stomatal status. Hydrophilic polymer amendment did not interact with antitranspirant GLK-8924 on all variables measured. The application of antitranspirant GLK-8924 was demonstrated to be useful for regulating plant water status, plant growth, and protecting plants from short-term water stress.
\end{abstract}

Plants grown in containers with a limited quantity of media require frequent irrigation to maintain adequate moisture. Stomatal regulation of transpiration is one mechanism that delays the occurrence of plant water stress due to soil water shortage (Bois et al., 1985). Photosynthesis and plant growth are also reduced by water stress, and rewatering usually enables plants to recover from water stress within a few hours to a few days (Akey and Morrison, 1984; Flore et al., 1985; Jorba and Tapia, 1985; Knapp and Smith, 1988; Natali et al., 1985).

Transpirational water loss may be reduced by either covering the stomata with film-forming antitranspirants or inducing stomatal closure with metabolic antitranspirants (Waisel et al., 1969; Walker and Zelitch, 1963). Sto-

Received for publication 31 July 1995. Accepted for publication 7 Mar. 1996. Oregon State Univ. horticulture technical paper 10921. The research was conducted at Oregon State Univ. We thank Tera Bonney for her technical assistance. The cost of publishing this paper was defrayed in part by the payment of page charges. Under postal regulations, this paper therefore must be hereby marked advertisement solely to indicate this fact.

${ }^{1}$ Assistant professor.

${ }^{2}$ Professor.

${ }^{3}$ Graduate research assistant.

${ }^{4}$ Research scientist.
Fig. 1. Leaf stomatal conductance and transpiration rate of 'Better Boy' tomato plants grown in media with or without short-term water stress and treated with antitranspirant GLK-8924, relative to well-irrigated plants treated with no antitranspirant GLK-8924 (CK). Water-stressed plants were rewatered 3 days after water-withholding. Each point is the mean of 15 plants, pooled for all the hydrophilic polymer amendments.
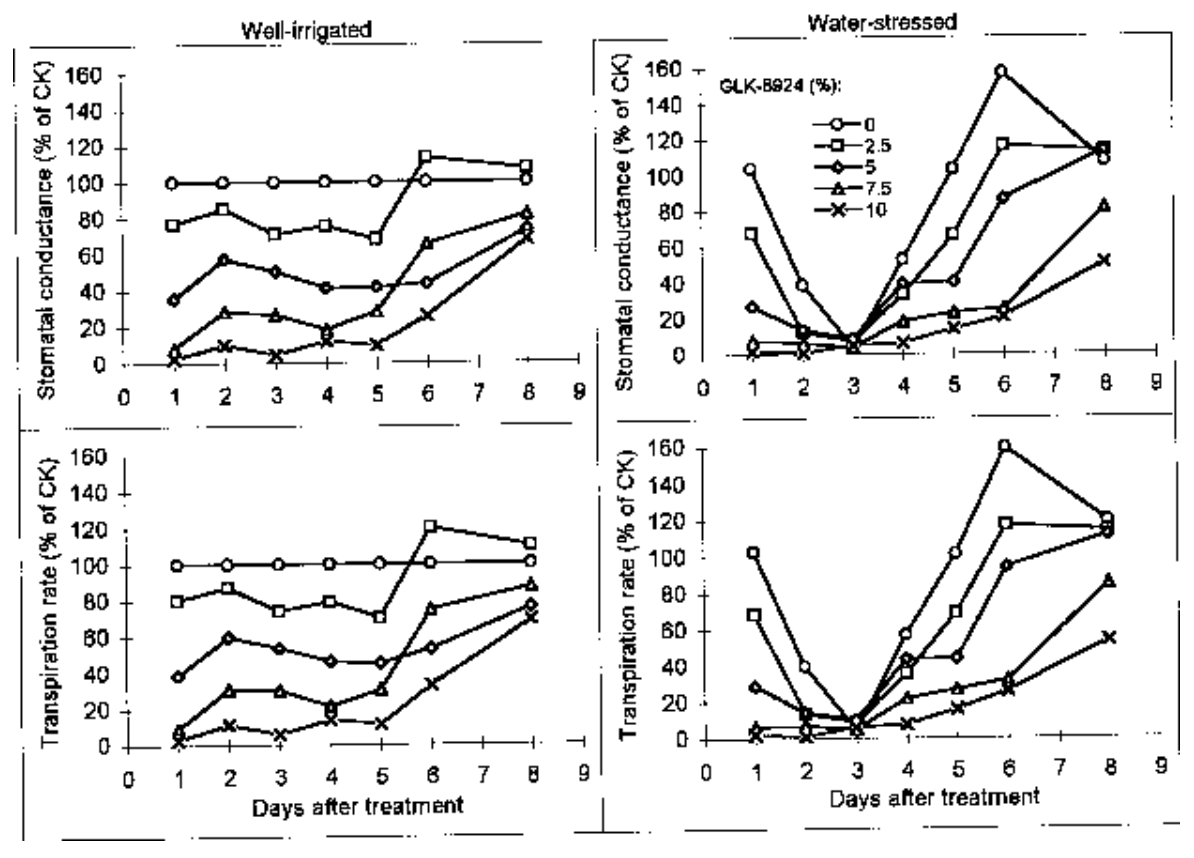
Table 1. Effects of short-term water stress, hydrophilic polymer amendment, and antitranspirant GLK-8924 on leaf stomatal conductance in 'Better Boy' tomato plants.

\begin{tabular}{|c|c|c|c|c|c|c|c|}
\hline & \multicolumn{7}{|c|}{ Days after water withholding and GLK-8924 application } \\
\hline & 1 & 2 & 3 & 4 & 5 & 6 & 8 \\
\hline \multicolumn{8}{|c|}{ Leaf stomatal conductance $\left(\mathrm{m} \cdot \mathrm{s}^{-1}\right)$} \\
\hline \multicolumn{8}{|l|}{ Water stress (WS) } \\
\hline Well-irrigated & 0.30 & $0.43 \mathrm{a}^{\mathrm{z}}$ & $0.38 \mathrm{a}$ & $0.34 \mathrm{a}$ & 0.28 & 0.21 & 0.31 \\
\hline Water-stressed ${ }^{y}$ & 0.28 & $0.11 \mathrm{~b}$ & $0.04 \mathrm{~b}$ & $0.21 \mathrm{~b}$ & 0.28 & 0.25 & 0.34 \\
\hline \multicolumn{8}{|c|}{ Hydrophilic polymer (HP) } \\
\hline Powdered & 0.31 & 0.29 & 0.24 & 0.28 & 0.29 & 0.20 & 0.34 \\
\hline Crystalline & 0.27 & 0.24 & 0.20 & 0.28 & 0.24 & 0.24 & 0.33 \\
\hline None & 0.27 & 0.26 & 0.19 & 0.26 & 0.30 & 0.24 & 0.32 \\
\hline \multicolumn{8}{|l|}{ GLK-8924 (G) \% } \\
\hline 0 & 0.68 & 0.53 & 0.39 & 0.52 & 0.57 & 0.39 & 0.38 \\
\hline 2.5 & 0.48 & 0.37 & 0.29 & 0.37 & 0.38 & 0.35 & 0.40 \\
\hline 5 & 0.21 & 0.27 & 0.22 & 0.28 & 0.23 & 0.20 & 0.34 \\
\hline 7.5 & 0.05 & 0.13 & 0.11 & 0.13 & 0.14 & 0.14 & 0.30 \\
\hline 10 & 0.01 & 0.04 & 0.04 & 0.06 & 0.07 & 0.07 & 0.22 \\
\hline Regression & $\mathrm{L}^{*}$ & $\mathrm{~L}^{*}$ & $\mathrm{~L}^{*}$ & $\mathrm{~L}^{*}$ & $\mathrm{~L}^{* *} \mathrm{Q}^{*}$ & NS & NS \\
\hline \multicolumn{8}{|l|}{ Significance } \\
\hline WS & NS & $* * *$ & $* * *$ & $* * *$ & NS & NS & NS \\
\hline $\mathrm{HP}$ & NS & NS & NS & NS & NS & NS & NS \\
\hline $\mathrm{G}$ & $* * *$ & $* * *$ & $* * *$ & $* * *$ & $* * *$ & $* * *$ & $*$ \\
\hline $\mathrm{WS} \times \mathrm{HP}$ & NS & NS & NS & NS & NS & NS & NS \\
\hline $\mathrm{WS} \times \mathrm{G}$ & NS & $* * *$ & $* * *$ & $* * *$ & NS & $*$ & NS \\
\hline $\mathrm{HP} \times \mathrm{G}$ & NS & NS & NS & NS & NS & NS & NS \\
\hline $\mathrm{WS} \times \mathrm{HP} \times \mathrm{G}$ & NS & NS & NS & NS & NS & NS & NS \\
\hline
\end{tabular}

$\overline{{ }^{\mathrm{z}} \text { Means within columns for each factor followed by different letters are significantly different by } t \text { test (water stress) or Duncan's }}$ multiple range test (hydrophilic polymer) at $P=0.05$.

${ }^{y}$ Water-stressed plants were rewatered 3 days after water withholding.

Ns,********* Nonsignificant or significant at $P=0.05,0.01$, and 0.001 , respectively. $\mathrm{L}=$ linear; $\mathrm{Q}=$ quadratic.

matal closure has been induced in herbaceous plants by leaf applications of abscisic acid (ABA) (Jones and Mansfield, 1970; Kriedmann et al., 1972). In Fraxinus, one ABA application reduced transpiration for 21 days. In preliminary experiments, the antitranspirant GLK-8924 (U.S. Patent, Great Lakes Chemical Co., West Lafayette, Ind.) reduced plant transpirational water loss by causing stomatal closure in several plant species.

Water-absorbing hydrophilic polymers, which absorb many times their weight of water, are also promoted for their potential to increase the water-holding capacity, aeration, and drainage of container media and reduce watering requirements of plants (Lamont and O'Connell, 1987; Orzolek, 1993; Tu et al., 1985). Plant survival and growth were also increased by hydrophilic polymer amendments (Fonteno and Bilderback, 1993; Save et al., 1995; Tripepi et al., 1991).

The objective of this study was to determine the effects of shortterm water stress, hydrophilic polymer amendment, and antitranspirant GLK-8924 application on leaf stomatal conductance, transpiration rate, transpirational water loss, growth, and dry-matter production in 'Better Boy' tomato plants.

\section{Materials and Methods}

Plant materials. Seedling plugs of 'Better Boy' tomato (Lycopersicon esculentum) plants, 4 days after true leaf emergence, were obtained from Peoria Garden, Peoria, Ore., and transplanted into $5.6 \times 8.2-\mathrm{cm}\left(200-\mathrm{cm}^{3}\right)$ square plastic pots (Anderson Die and MFG Co. Portland, Ore.) on 15 Mar. 1994 with a medium containing $60 \%$ processed fiber (a by-product of anaerobically digested dairy wastes, Unisyn BioWaste Technology, Seattle, Wash.) and
$40 \%$ perlite (no. 3 coarse horticulture propagation grade, Supreme Perlite Co., Portland, Ore.), by volume. Plants were grown in a greenhouse with $25{ }^{\circ} \mathrm{C}$ day $/ 21^{\circ} \mathrm{C}$ night temperature cycles and sodium vapor artificial light supplement $\left(200 \mu \mathrm{mol} \cdot \mathrm{m}^{-2} \cdot \mathrm{s}^{-1}\right.$, from 0500 to $2000 \mathrm{HR}$ ), fertilized with Nutricote Total controlled-release fertilizer (type $100,13 \mathrm{~N}-5.67 \mathrm{P}-10.79 \mathrm{~K}$ plus micronutrients, Chisso-Asahi Fertilizer Co. Ltd. Tokyo), and irrigated to prevent water stress when necessary. Pots were last irrigated to container capacity on 27 Mar., and then no water was supplied until plants were treated with antitranspirant GLK-8924 on 29 Mar. Plant spacing was increased according to the plant growth on the greenhouse bench to avoid shading.

Experimental design. The experiment consisted of a factorial combination of two short-term water stress levels (well-irrigated and water-stressed), three hydrophilic polymer amendments (none, crystalline, and powdered hydrophilic polymer, WaterWorks Crystals acrylamide-potassium-acrylate copolymer, WaterWorks America, Inc., North Royalton, Ohio), and five antitranspirant GLK-8924 concentrations $(0 \%, 2.5 \%, 5 \%, 7.5 \%$, or $10 \%)$. The experimental design was a randomized complete block with five replications. Hydrophilic polymers were added at the time of transplanting at a rate of $2.4 \mathrm{~kg} \cdot \mathrm{m}^{-3}$ on $15 \mathrm{Mar}$. The antitranspirant GLK-8924 was applied to the medium at a rate of $40 \mathrm{~mL} /$ pot on 29 Mar. The pots were placed on petri-dish lids to prevent loss of antitranspirant GLK-8924 from the media. Watering of pots assigned to short-term water stress was withheld for 3 days after the antitranspirant GLK-8924 application and resumed thereafter. Well-irrigated plants were watered daily with an amount of water equivalent to the evapotranspiration water loss determined as weight decrease of the pot and plant. Data were statistically 
Table 2. Effects of short-term water stress, hydrophilic polymer amendment, and antitranspirant GLK-8924 on leaf transpiration rate in 'Better Boy' tomato plants.

\begin{tabular}{|c|c|c|c|c|c|c|c|}
\hline & \multicolumn{7}{|c|}{ Days after water withholding and GLK-8924 application } \\
\hline & 1 & 2 & 3 & 4 & 5 & 6 & 8 \\
\hline \multicolumn{8}{|c|}{ Leaf transpiration rate $\left(\mu \mathrm{g} \cdot \mathrm{cm}^{-2} \cdot \mathrm{s}^{-1}\right)$} \\
\hline \multicolumn{8}{|l|}{ Water stress (WS) } \\
\hline Well-irrigated & 2.25 & $3.41 \mathrm{a}^{\mathrm{z}}$ & $3.31 \mathrm{a}$ & $3.04 \mathrm{a}$ & 2.63 & 2.38 & 2.48 \\
\hline Water-stressed ${ }^{y}$ & 2.04 & $0.88 \mathrm{~b}$ & $0.42 \mathrm{~b}$ & $1.93 \mathrm{~b}$ & 2.61 & 2.68 & 2.70 \\
\hline \multicolumn{8}{|c|}{ Hydrophilic polymer (HP) } \\
\hline Powdered & 2.32 & 2.31 & 2.10 & 2.45 & 2.73 & 2.20 & 2.65 \\
\hline Crystalline & 2.09 & 2.02 & 1.80 & 2.56 & 2.30 & 2.76 & 2.57 \\
\hline None & 2.03 & 2.11 & 1.69 & 2.44 & 2.82 & 2.64 & 2.56 \\
\hline \multicolumn{8}{|l|}{ GLK-8924 (G) \% } \\
\hline 0 & 4.96 & 4.11 & 3.28 & 4.58 & 5.13 & 4.06 & 3.07 \\
\hline 2.5 & 3.63 & 2.97 & 2.60 & 3.34 & 3.55 & 3.71 & 3.13 \\
\hline 5 & 1.65 & 2.18 & 2.01 & 2.62 & 2.26 & 2.31 & 2.63 \\
\hline 7.5 & 0.37 & 1.11 & 1.08 & 1.26 & 1.46 & 1.67 & 2.40 \\
\hline 10 & 0.11 & 0.35 & 0.37 & 0.62 & 0.69 & 0.92 & 1.72 \\
\hline Regression & $\mathrm{L}^{*}$ & $\mathrm{~L}^{*}$ & $\mathrm{~L}^{*}$ & $\mathrm{~L}^{*}$ & $\mathrm{~L}^{* *} \mathrm{Q}^{*}$ & NS & NS \\
\hline \multicolumn{8}{|l|}{ Significance } \\
\hline WS & NS & $* * *$ & $* * *$ & $* * *$ & NS & NS & NS \\
\hline HP & NS & NS & NS & NS & NS & NS & NS \\
\hline G & $* * *$ & $* * *$ & $* * *$ & $* * *$ & $* * *$ & $* * *$ & $*$ \\
\hline $\mathrm{WS} \times \mathrm{HP}$ & NS & NS & NS & NS & NS & NS & NS \\
\hline $\mathrm{WS} \times \mathrm{G}$ & NS & $* * *$ & $* * *$ & $* * *$ & NS & $*$ & NS \\
\hline $\mathrm{HP} \times \mathrm{G}$ & NS & NS & NS & NS & NS & NS & NS \\
\hline $\mathrm{WS} \times \mathrm{HP} \times \mathrm{G}$ & NS & NS & NS & NS & NS & NS & NS \\
\hline
\end{tabular}

${ }^{\mathrm{z}}$ Means within columns for each factor followed by different letters are significantly different by $t$ test (water stress) or Duncan's multiple range test (hydrophilic polymer) at $P=0.05$.

${ }^{\mathrm{y}}$ Water-stressed plants were rewatered 3 days after water withholding.

Ns,***,**** Nonsignificant or significant at $P=0.05,0.01$, and 0.001 , respectively. $\mathrm{L}=$ linear; $\mathrm{Q}=$ quadratic.

examined by analysis of variance, correlation, and regression analysis of selected variables.

Leaf stomatal conductance and transpiration rate. Leaf stomatal conductance and transpiration rate were measured daily for the first 6 days after water withholding and antitranspirant GLK8924 application and then every 2 or 3 days until plants were harvested for dry-weight determination. Measurements were conducted on fully developed leaflets of the third or fourth true leaf with a steady-state porometer (LI-1600; LI-COR, Lincoln, Neb.) between 1000 to $1300 \mathrm{HR}$.

Transpirational water loss. Fresh weights of the pots with plants were determined daily until the eighth day after water withholding and antitranspirant GLK-8924 application. Evaporation was measured for pots filled with media only (no plants) and treated with antitranspirant GLK-8924 solutions at the same concentrations. Plant transpirational water loss was calculated as the daily fresh weight difference of the pots with plant minus the evaporational water loss (calculated as the daily fresh weight difference of the pots without plants), and plant fresh weight increases were obtained from another set of plants with the same treatments.

Plant height and dry weight determination. Plant height above the medium surface was measured daily with a ruler for the first 7 days after water withholding and antitranspirant GLK-8924 application and every 2 or 3 days thereafter until plants were harvested for determining top dry weight. Plant growth rate was expressed as the daily increase in plant height. Well-irrigated and short-term water-stressed plants were harvested for top dry weight 8 and 13 days, respectively, after the water withholding and antitranspirant GLK-8924 application. The short-term water stressed plants were harvested later to monitor the plant responses to antitranspirant GLK-8924 application.

\section{Results}

Stomatal conductance and transpiration rate. Stomatal conductance and transpiration rate were significantly reduced by short-term water stress, and the depression was reversed completely in 2 days after rewatering (Fig. 1) but was not influenced by hydrophilic polymer amendments (Tables 1 and 2). Antitranspirant GLK-8924 reduced stomatal conductance and the transpiration rate linearly for 5 days as concentration increased (Tables 1 and 2). Water stress and antitranspirant GLK-8924 interacted on the second, third, fourth, and sixth days to affect stomatal conductance and transpiration rate (Tables 1 and 2). Water-stressed plants showed less effect of antitranspirant GLK-8924 starting the second day of water withholding until watering resumed compared to well-watered plants. Stomatal conductance and the transpiration rate of short-term water stressed plants were much lower during water stress than well-watered plants, but recovered to a level of 1.5 times that of the well-irrigated plants on the third day after watering was resumed (Fig. 1).

Evaporational and transpirational water loss. The rate of evaporation was not affected by antitranspirant GLK-8924 (data not shown). Plant transpirational water loss was reduced by shortterm water stress and antitranspirant GLK-8924 but enhanced by hydrophilic polymer amendment (Fig. 2, Table 3). Transpirational water loss was linearly correlated and inversely proportional to the concentration of antitranspirant GLK-8924 during the nonwaterstressed period (Table 3). 

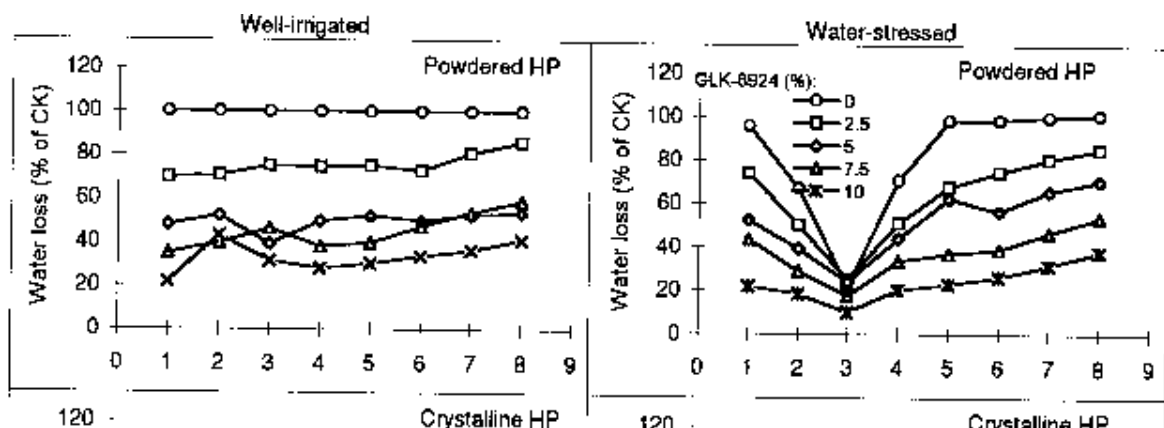

Water-stressed
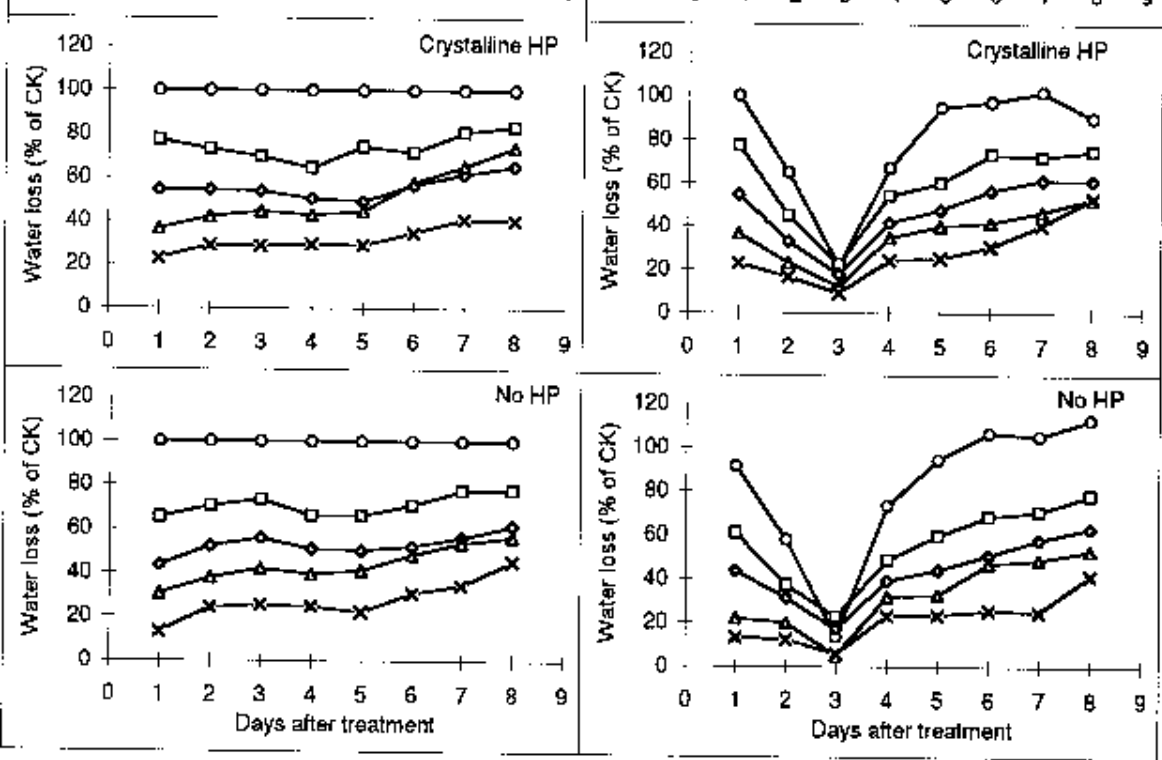

Fig. 2. Transpirational water loss of 'Better Boy' tomato plants grown in media with or without short-term water stress or hydrophilic polymer (HP) amendment and treated with antitranspirant GLK-8924, relative to well-irrigated plants treated with no antitranspirant GLK-8924 (CK). Water-stressed plants were rewatered 3 days after waterwithholding. Each point is the mean of five plants.

Plant growth and biomass production. Short-term water stress resulted in smaller plants (Table 4). Growth rate, however, recovered immediately after rewatering (Table 5). Water-stressed plants reached similar height as well-irrigated plants 4 days after watering was resumed (Table 4). Powdered hydrophilic polymer amendment improved plant height slightly over the crystalline and no hydrophilic polymer amendments (Table 4). Antitranspirant GLK-8924 concentration was linearly correlated and inversely proportional to plant height 1 and 2 days and to plant growth rate 1 and 3 days after antitranspirant GLK8924 application (Tables 4 and 5).

Plant top dry weight was reduced by antitranspirant GLK-8924 applications and increased by the powdered or crystalline hydrophilic polymer amendment for well-irrigated and water-stressed plants compared to plants in medium with no hydrophilic polymer amendment (Table 6). Hydrophilic polymer

Table 3. Effects of short-term water stress, hydrophilic polymer amendment, and antitranspirant GLK-8924 on transpirational water loss in 'Better Boy' tomato plants.

\begin{tabular}{|c|c|c|c|c|c|c|c|c|}
\hline & \multicolumn{8}{|c|}{ Days after water withholding and GLK-8924 application } \\
\hline & 1 & 2 & 3 & 4 & 5 & 6 & 7 & 8 \\
\hline \multicolumn{9}{|c|}{ Transpirational water loss $\left(g \cdot d^{-1}\right)$} \\
\hline \multicolumn{9}{|l|}{ Water stress (WS) } \\
\hline Well-irrigated & 12 & $16 \mathrm{a}^{\mathrm{z}}$ & $19 \mathrm{a}$ & $20 \mathrm{a}$ & $24 \mathrm{a}$ & 27 & 27 & 24 \\
\hline Water-stressed ${ }^{\mathrm{y}}$ & 12 & $10 \mathrm{~b}$ & $5 \mathrm{~b}$ & $15 \mathrm{~b}$ & $22 \mathrm{~b}$ & 26 & 26 & 24 \\
\hline \multicolumn{9}{|c|}{ Hydrophilic polymer (HP) } \\
\hline Powdered & 13 & $14 \mathrm{a}$ & $14 \mathrm{a}$ & $19 \mathrm{a}$ & $24 \mathrm{a}$ & 27 & $27 \mathrm{a}$ & $26 \mathrm{a}$ \\
\hline Crystalline & 13 & $13 \mathrm{a}$ & $13 \mathrm{~b}$ & $17 \mathrm{~b}$ & $23 \mathrm{ab}$ & 26 & $27 \mathrm{a}$ & $24 \mathrm{a}$ \\
\hline None & 11 & $11 \mathrm{~b}$ & $11 \mathrm{c}$ & $16 \mathrm{c}$ & $23 \mathrm{~b}$ & 26 & $24 \mathrm{~b}$ & $21 \mathrm{~b}$ \\
\hline \multicolumn{9}{|l|}{ GLK-8924 (G) \% } \\
\hline 0 & 22 & 21 & 20 & 29 & 41 & 43 & 41 & 35 \\
\hline 2.5 & 16 & 15 & 16 & 21 & 28 & 31 & 31 & 28 \\
\hline 5 & 11 & 11 & 11 & 16 & 21 & 23 & 24 & 22 \\
\hline 7.5 & 8 & 8 & 9 & 13 & 16 & 20 & 21 & 20 \\
\hline 10 & 4 & 6 & 6 & 9 & 11 & 13 & 14 & 15 \\
\hline Regression & $\mathrm{L}^{* * *} \mathrm{Q}^{* *}$ & $\mathrm{~L}^{* *} \mathrm{Q}^{*}$ & $\mathrm{~L}^{*}$ & $\mathrm{~L}^{*}$ & $\mathrm{~L}^{*}$ & $\mathrm{~L}^{*}$ & $\mathrm{~L}^{*}$ & $\mathrm{~L}^{*}$ \\
\hline \multicolumn{9}{|l|}{ Significance } \\
\hline WS & NS & $* * *$ & $* * *$ & $* * *$ & $* *$ & NS & NS & NS \\
\hline HP & $* * *$ & $* * *$ & $* * *$ & $* * *$ & $*$ & NS & $*$ & $* * *$ \\
\hline $\mathrm{G}$ & $* * *$ & $* * *$ & $* * *$ & $* * *$ & $* * *$ & $* * *$ & $* * *$ & $* * *$ \\
\hline $\mathrm{WS} \times \mathrm{HP}$ & NS & NS & NS & NS & NS & NS & NS & NS \\
\hline $\mathrm{WS} \times \mathrm{G}$ & NS & $* * *$ & $* * *$ & $* * *$ & NS & NS & NS & NS \\
\hline $\mathrm{HP} \times \mathrm{G}$ & NS & NS & NS & NS & NS & NS & NS & NS \\
\hline $\mathrm{WS} \times \mathrm{HP} \times \mathrm{G}$ & NS & NS & NS & NS & NS & NS & NS & NS \\
\hline
\end{tabular}

${ }^{\mathrm{z}}$ Means within columns for each factor followed by different letters are significantly different by $t$ test (water stress) or Duncan's multiple range test (hydrophilic polymer) at $P=0.05$.

yWater-stressed plants were rewatered 3 days after water withholding.

Ns,******** Nonsignificant or significant at $P=0.05,0.01$, and 0.001 , respectively. $\mathrm{L}=$ linear; $\mathrm{Q}=$ quadratic. 
Table 4. Effects of short-term water stress, hydrophilic polymer amendment, and antitranspirant GLK-8924 on plant height in 'Better Boy' tomato plants.

\begin{tabular}{|c|c|c|c|c|c|c|c|c|c|}
\hline & \multicolumn{9}{|c|}{ Days after water withholding and GLK-8924 application } \\
\hline & 0 & 1 & 2 & 3 & 4 & 5 & 6 & 7 & 8 \\
\hline \multicolumn{10}{|c|}{ Plant ht $(\mathrm{mm})$} \\
\hline \multicolumn{10}{|l|}{ Water stress (WS) } \\
\hline Well-irrigated & 143 & $154 b^{2}$ & 160 & $166 \mathrm{a}$ & $175 \mathrm{a}$ & $181 \mathrm{a}$ & $187 \mathrm{a}$ & 193 & \\
\hline Water-stressed ${ }^{y}$ & 148 & $158 \mathrm{a}$ & 161 & $163 \mathrm{~b}$ & $171 \mathrm{~b}$ & $177 \mathrm{~b}$ & $183 \mathrm{~b}$ & 190 & \\
\hline \multicolumn{10}{|c|}{ Hydrophilic polymer (HP) } \\
\hline Powdered & 148 & $160 \mathrm{a}$ & $165 \mathrm{a}$ & $170 \mathrm{a}$ & $179 \mathrm{a}$ & $185 \mathrm{a}$ & $190 \mathrm{a}$ & $197 \mathrm{a}$ & $206 \mathrm{a}$ \\
\hline Crystalline & 144 & $154 b$ & $158 \mathrm{~b}$ & $163 \mathrm{~b}$ & $171 \mathrm{~b}$ & $178 \mathrm{~b}$ & $184 \mathrm{~b}$ & $191 \mathrm{~b}$ & $192 b$ \\
\hline None & 145 & $154 \mathrm{~b}$ & $158 \mathrm{~b}$ & $161 \mathrm{~b}$ & $170 \mathrm{~b}$ & $175 \mathrm{~b}$ & $181 \mathrm{~b}$ & $186 \mathrm{~b}$ & $190 \mathrm{~b}$ \\
\hline \multicolumn{10}{|l|}{ GLK-8924 (G) \% } \\
\hline 0 & 146 & 164 & 172 & 178 & 188 & 195 & 203 & 210 & 213 \\
\hline 2.5 & 145 & 159 & 165 & 170 & 179 & 185 & 190 & 198 & 201 \\
\hline 5 & 146 & 155 & 160 & 164 & 174 & 181 & 186 & 192 & 198 \\
\hline 7.5 & 148 & 154 & 156 & 159 & 168 & 174 & 180 & 186 & 192 \\
\hline 10 & 144 & 149 & 150 & 152 & 157 & 161 & 167 & 172 & 175 \\
\hline Regression & NS & NS & $\mathrm{L}^{*}$ & $\mathrm{~L}^{*}$ & NS & NS & NS & NS & NS \\
\hline \multicolumn{10}{|l|}{ Significance } \\
\hline WS & NS & $* *$ & NS & $*$ & $*$ & $*$ & $*$ & NS & \\
\hline $\mathrm{HP}$ & NS & $* * *$ & $* * *$ & $* * *$ & $* * *$ & $* * *$ & $* * *$ & $* * *$ & $* * *$ \\
\hline $\mathrm{G}$ & NS & $* * *$ & $* * *$ & $* * *$ & $* * *$ & $* * *$ & $* * *$ & $* * *$ & $* * *$ \\
\hline $\mathrm{WS} \times \mathrm{HP}$ & NS & NS & NS & NS & NS & NS & NS & NS & \\
\hline $\mathrm{WS} \times \mathrm{G}$ & NS & NS & NS & NS & NS & NS & NS & NS & \\
\hline $\mathrm{HP} \times \mathrm{G}$ & NS & NS & NS & NS & NS & NS & NS & NS & NS \\
\hline $\mathrm{WS} \times \mathrm{HP} \times \mathrm{G}$ & NS & NS & NS & NS & NS & NS & NS & NS & \\
\hline
\end{tabular}

${ }^{\bar{z}}$ Means within columns for each factor followed by different letters are significantly different by $t$ test (water stress) or Duncan's multiple range test (hydrophilic polymer) at $P=0.05$.

${ }^{\mathrm{y}}$ Water-stressed plants were rewatered 3 days after water withholding.

Ns,***,*** Nonsignificant or significant at $P=0.05,0.01$, and 0.001 , respectively. $\mathrm{L}=$ linear.

amendment did not interact significantly with antitranspirant GLK8924 on dry weight of plant tops. Plant growth rate, leaf stomatal conductance, transpiration rate, and transpirational water loss were well correlated to each other. The correlation was strongest when short-term water stress effect was significant (Table 7).

Interactions. Short-term water stress and antitranspirant GLK8924 interacted to affect transpirational water loss on the second, third, and fourth day after water withholding and antitranspirant GLK-8924 application. Short-term water stress interacted significantly with antitranspirant GLK-8924 but not with hydrophilic polymer on leaf stomatal conductance, transpiration rate, and transpirational water loss during the period of water stress (Tables $1-3$ ). Water stress reduced these variables to very low levels (Figs. 1 and 2). Hydrophilic polymer did not significantly interact with antitranspirant GLK-8924 on any of the measured variables. Water stress interacted with hydrophilic polymer on plant growth rate 3 days after water withholding and the antitranspirant GLK-8924 application, when the plants were most stressed. Interactions of water stress with hydrophilic polymer and water stress with antitranspirant GLK-8924 on plant growth rate were significant only on the third day after water withholding and the antitranspirant GLK-8924 application when the water stress was greatest (Table 6).

\section{Discussion}

Short-term water stress. Plant transpirational water loss was reduced to about $26 \%$ by short-term water stress, when some of the plants started wilting, compared to well-irrigated plants. Stomatal conductance was reduced and was highly correlated to transpirational water loss, suggesting that water stress reduced water loss by inducing stomatal closure. The negative effect of short-term water stress was temporary and was reversed by rewatering, with complete recovery in 2 days. The over-recovery of stomatal conductance and transpiration rate was also temporary. Fischer et al. (1970) reported similar findings in grain sorghum (Sorghum vulgare). The reduction of plant growth caused by water stress was maintained after rehydration. This is consistent with results reported in a wide diversity of species (Akey and Morrison, 1984; Flore et al., 1985; Jorba et al., 1985; Knapp and Smith, 1988; Natali et al., 1985). Transpiration and photosynthesis are reduced by stomatal resistance during short periods of drought (Hansen, 1971; Hsiao, 1973), and the suppressing effect of water stress on photosynthesis often disappears within a few hours after restoring the water supply (Hari and Luukkanen, 1973).

Hydrophilic polymer amendment. The hydrophilic polymer amendment does not influence the plant responses caused by antitranspirant GLK-8924, including leaf stomatal conductance and transpiration rate. Thus, the hydrophilic polymer amendment may have increased plant transpirational water loss by promoting plant growth through its effect on nutrients and water availability rather than on stomatal characteristics. Compared to plants grown in hydrophilic polymer-amended media, European birch (Betula pendula Roth) plants growing in media without hydrophilic polymer had significantly lower stomatal conductance and transpiration on less than $25 \%$ of the measurement dates (Tripepi et al., 1991). Spider plants (Chlorophytum comosum Thunb) grown in medium with $10 \%$ hydrophilic polymer were $50 \%$ larger and had more lateral shoots and better root systems than control plants (Wang and Boogher, 1987). In contrast, hydrophilic polymer had no effect on the growth of other tropical ornamental plants (Wang, 
Table 5. Effects of short-term water stress, hydrogel amendment, and antitranspirant GLK-8924 on growth rate in 'Better Boy' tomato plants.

\begin{tabular}{|c|c|c|c|c|c|c|c|c|}
\hline & \multicolumn{8}{|c|}{ Days after water withholding and GLK-8924 application } \\
\hline & 1 & 2 & 3 & 4 & 5 & 6 & 7 & 8 \\
\hline \multicolumn{9}{|c|}{ Plant growth rate $\left({\left.\mathrm{mm} \cdot \mathrm{d}^{-1}\right)}\right.$} \\
\hline \multicolumn{9}{|l|}{ Water Stress (WS) } \\
\hline Well-irrigated & 11 & $6 \mathrm{a}$ & $6 \mathrm{a}$ & 9 & 6 & 6 & 6 & \\
\hline Water-stressed & 10 & $3 \mathrm{~b}$ & $2 \mathrm{~b}$ & 9 & 6 & 6 & 7 & \\
\hline \multicolumn{9}{|c|}{ Hydrophilic polymer (HP) } \\
\hline Powdered & $12 \mathrm{a}$ & 5 & $5 \mathrm{a}$ & 8 & 6 & 6 & 7 & 7 \\
\hline Crystalline & $10 \mathrm{~b}$ & 5 & $4 a b$ & 9 & 7 & 6 & 7 & 6 \\
\hline None & $8 \mathrm{~b}$ & 4 & $3 \mathrm{~b}$ & 9 & 5 & 6 & 5 & 5 \\
\hline \multicolumn{9}{|l|}{ GLK-8924 (G) \% } \\
\hline 0 & 18 & 8 & 6 & 11 & 7 & 8 & 7 & 6 \\
\hline 2.5 & 13 & 6 & 5 & 9 & 6 & 5 & 8 & 6 \\
\hline 5 & 9 & 5 & 4 & 10 & 6 & 6 & 6 & 6 \\
\hline 7.5 & 6 & 2 & 3 & 9 & 6 & 6 & 6 & 7 \\
\hline 10 & 5 & 2 & 2 & 5 & 4 & 5 & 6 & 5 \\
\hline Regression & $\mathrm{L}^{* *} \mathrm{Q}^{*}$ & NS & $\mathrm{L}^{*} \mathrm{Q}^{* *}$ & NS & NS & NS & NS & NS \\
\hline \multicolumn{9}{|l|}{ Significance } \\
\hline WS & NS & $* * *$ & $* * *$ & NS & NS & NS & NS & \\
\hline $\mathrm{HP}$ & $* * *$ & NS & $* *$ & NS & NS & NS & NS & NS \\
\hline G & $* * *$ & $* * *$ & $* * *$ & $* * *$ & NS & NS & NS & NS \\
\hline $\mathrm{WS} \times \mathrm{HP}$ & NS & NS & $*$ & NS & NS & NS & NS & \\
\hline $\mathrm{WS} \times \mathrm{G}$ & NS & NS & $* *$ & NS & NS & NS & NS & \\
\hline $\mathrm{HP} \times \mathrm{G}$ & NS & NS & NS & NS & NS & NS & NS & NS \\
\hline $\mathrm{WS} \times \mathrm{HP} \times \mathrm{G}$ & NS & NS & NS & NS & NS & NS & NS & \\
\hline
\end{tabular}

$\overline{{ }^{\mathrm{z}} \text { Means within columns for each factor followed by different letters are significantly different by } t \text { test (water stress) or Duncan's }}$ multiple range test (hydrophilic polymer) at $P=0.05$.

${ }^{\mathrm{y}}$ Water-stressed plants were rewatered 3 days after water withholding.

$\mathrm{Ns}, * * *, * * * *$ Nonsignificant or significant at $P=0.05,0.01$, and 0.001 , respectively. $\mathrm{L}=$ linear; $\mathrm{Q}=$ quadratic.

Table 6. Effects of hydrogel amendment and antitranspirant GLK-8924 on plant top dry weight in well-watered or water-stressed 'Better Boy' tomato plants.

\begin{tabular}{|c|c|c|}
\hline & \multicolumn{2}{|c|}{ Plant top dry wt $(\mathrm{g})$} \\
\hline & Well-watered & Water-stressed $^{\mathrm{z}}$ \\
\hline \multicolumn{3}{|c|}{ Hydrophilic polymer (HP) } \\
\hline Powdered & $1.89 \mathrm{a}^{\mathrm{y}}$ & $3.09 \mathrm{a}$ \\
\hline Crystalline & $1.97 \mathrm{a}$ & $2.81 \mathrm{a}$ \\
\hline None & $1.79 \mathrm{~b}$ & $2.52 \mathrm{~b}$ \\
\hline \multicolumn{3}{|c|}{ GLK-8924 (G) \% } \\
\hline 0 & 2.38 & 3.55 \\
\hline 2.5 & 2.04 & 3.08 \\
\hline 5 & 1.81 & 2.72 \\
\hline 7.5 & 1.73 & 2.57 \\
\hline 10 & 1.47 & 2.13 \\
\hline Regression & NS & NS \\
\hline \multicolumn{3}{|l|}{ Significance } \\
\hline $\mathrm{HP}$ & $* *$ & $* * *$ \\
\hline $\mathrm{G}$ & $* * *$ & $* * *$ \\
\hline $\mathrm{HP} \times \mathrm{G}$ & NS & NS \\
\hline \multicolumn{3}{|c|}{$\begin{array}{l}{ }^{z} \text { Water-stressed plants were rewatered } 3 \text { days after water withholding. } \\
\text { Well-watered and water-stressed plants were harvested } 8 \text { or } 13 \text { days after } \\
\text { water-withholding and GLK-8924 application, respectively. } \\
\text { 'Means within columns for each factor followed by different letters are } \\
\text { significantly different by Duncan's multiple range test at } P=0.05 \text {. } \\
\text { Ns,*,**,*** Nonsignificant or significant at } P=0.05,0.01 \text {, and } 0.001 \text {, } \\
\text { respectively. }\end{array}$} \\
\hline
\end{tabular}

1989) and Boston ferns (Neohrolepis exaltata L.) (Wang and Boogher, 1987).

Antitranspirant GLK-8924. The effect of antitranspirant GLK8924 on leaf stomatal status and transpiration was similar to shortterm water stress and lasted for 5 to 7 days (Table 2). The antitranspirant GLK-8924 is reported to induce stomatal closure by exposing plants to osmotic stress. Plant transpirational water loss was successfully regulated by antitranspirant GLK-8924 application. Controlled regulation of stomatal closure with antitranspirant GLK-8924 would reduce water loss and plant growth when soil moisture is adequate. The reduction in plant growth between antitranspirant GLK-8924 and short-term water stress-treated plants was similar and was probably due to reduced gas exchange and, therefore, decreased photosynthesis caused by stomatal closure. The effect of antitranspirant GLK-8924 application on growth was concentration dependent and suggests a possible means of regulating plant growth and protecting plants from short-term water stress.

\section{Literature Cited}

Akey, W.C. and I.N. Morrison. 1984. Effects of soil moisture on the vegetative growth of wild oat (Avena fatua). Weed Sci. 32:625-630.

Bois, J.F., A. Orstom, P. Couchat, and G. Lasceve. 1985. Relationships between transpiration and photosynthesis during a water stress. Acta Hort. 171:297-304.

Fischer, R.A., T.C. Hsiao, and R.M. Hagan. 1970. After-effect of water stress on stomatal opening potential. J. Expt. Bot. 21: 371-385.

Flore, J.A., J.W. Moon, and A.N. Lakso. 1985. The effect of water stress 
Table 7. Correlation coefficients among stomatal conductance (SC), transpiration rate (TR), transpirational water loss (TWL), and growth rate (GR) in well-watered and water-stressed 'Better Boy' tomato plants treated with antitranspirant GLK-8924 at various concentrations.

\begin{tabular}{|c|c|c|c|c|c|c|c|}
\hline \multirow[b]{2}{*}{ Parameter } & \multicolumn{7}{|c|}{ Days after treatment } \\
\hline & 1 & 2 & 3 & 4 & 5 & 6 & 8 \\
\hline$\overline{\mathrm{SC} / \mathrm{TWL}}$ & $0.8437^{* * * *}$ & $0.7623^{* * * *}$ & $0.8676^{* * * *}$ & $0.8261^{\text {***** }}$ & $0.8133^{* * * *}$ & $0.6370^{* * * *}$ & $0.5621^{* * * *}$ \\
\hline SC/GR & $0.7243^{* * * *}$ & $0.6872^{* * *}$ & $0.6496^{* * *}$ & $0.2692^{* *}$ & NS & $0.3746^{* *}$ & NS \\
\hline TR/TWL & $0.8258^{* * * *}$ & $0.7461^{\text {**** }}$ & $0.8643^{* * *}$ & $0.8206^{* * * *}$ & $0.8085^{* * *}$ & $0.5976^{* * * *}$ & $0.5809^{* * * *}$ \\
\hline TR/GR & $0.7241^{* * * *}$ & $0.6818^{* * *}$ & $0.6600^{* * * *}$ & $0.2894^{* *}$ & $0.2488^{* *}$ & $0.3575^{* * *}$ & NS \\
\hline TWL/GR & $0.7094^{* * * *}$ & $0.6650^{* * *}$ & $0.7212^{* * *}$ & $0.3227^{* *}$ & $0.1968^{*}$ & $0.2296^{* * *}$ & NS \\
\hline
\end{tabular}

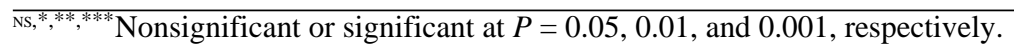

and vapor pressure gradient on stomatal conductance, water use efficiency, and photosynthesis of fruit crops. Acta Hort. 171:207-218.

Fonteno, W.C. and T.E. Bilderback. 1993. Impact of hydrogel on physical properties of coarse-structured horticultural substrates. J. Amer. Soc. Hort. Sci. 118:217-222.

Hansen, G.K. 1971. Photosynthesis, transpiration and diffusion resistance in relation to water potential in leaves during water stress. Acta Agr. Scand. 21:163-171.

Hari, P. and O. Luukkanen. 1973. Effect of water stress, temperature, and light on photosynthesis in alder seedlings. Physiol. Plant. 29:45-53.

Hsiao, T.C. 1973. Plant responses to water stress. Annu. Rev. Plant Physiol. 24:519-570.

Jones, R.J. and T.A. Mansfield. 1970. Suppression of stomatal opening in leaves treated with ABA. J. Expt. Bot. 21:714-718.

Jorba, J. and D.S. Tapia. 1985. Photosynthesis, leaf water potential, and stomatal conductance in Olea Europaea under wet and drought conditions. Acta Hort. 171:237-246.

Knapp, A.K and W.K. Smith. 1988. Effect of water stress on stomatal and photosynthetic responses in subalpine plants to cloud patterns. Amer. J. Bot. 75:851-858.

Kriedmann, P.E., B.R. Loveys, G.L. Fuller, and A.C. Leopold. 1972. Abscisic acid and stomatal regulation. Plant Physiol. 49:842-847.

Lamont, G.P. and M.A. O'Connell. 1987. Shelf life of bedding plants as influenced by potting media and hydrogels. Scientia Hort. 31:141-149.

Natali, S., C. Xiloyannis, and M. Castagneto. 1985. Effect of soil water content on leaf water potential and stomatal resistance of grapevine (Vitis vinifera) grafted on different rootstocks. Acta Hort. 171:331-340.

Orzolek, M.D. 1993. Use of hydrophylic polymers in horticulture. HortTechnology 3:41-44.

Save, R., M. Pery, O. Marfa, and L. Serrano. 1995. The effect of a hydrophilic polymer on plant water status and survival of transplanted pine seedlings. HortTechnology 5:141-143

Tripepi, R.R., M.W. George, R.K. Dumroese, and D.L. Wenny. 1991. Birch seedling response to irrigation frequency and a hydrophilic polymer amendment in a container medium. J. Environ. Hort. 9:119123

Tu, Z.P., A.M. Armitage, and H.M. Vines. 1985. Influence of an antitranspirant and a hydrogel on net photosynthesis and water loss of cinearia during water stress. HortScience 20:386-388.

Waisel, Y., G.A. Borger, and T.T. Kozlowski. 1969. Effects of phenylmercuric acetate on stomatal movement and transpiration of excised Betula papyrifera Marsh. leaves. Plant Physiol. 44:685-690.

Walker, D.A. and I. Zelitch. 1963. Some effects of metabolic inhibitors, temperature and anaerobic conditions on stomatal movement. Plant Physiol. 38:390-396.

Wang, Y.T. 1989. Medium and hydrogel affect production and wilting of tropical ornamental plants. HortScience 24:941-944.

Wang, Y.T. and C.A. Boogher. 1987. Effect of a medium-incorporated hydrogel on plant growth and water use of two foliage species. J. Environ. Hort. 5:127-130. 